\title{
Incentives for Mothers, Health Workers and "Boda-Boda" Riders to Improve Community-Based Referral Process and Deliveries in the Rural Community: A Case of Busoga Region in Uganda
}

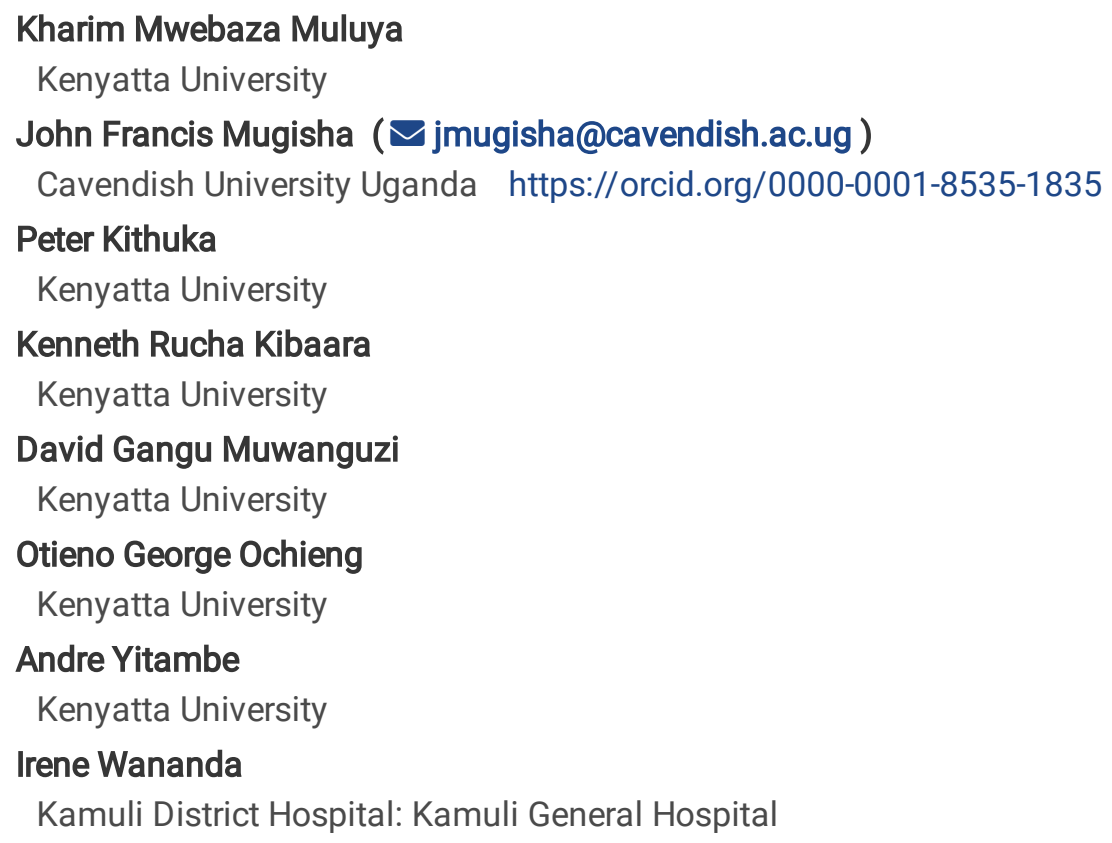




\section{Abstract}

Background: This study set out to investigate how incentives for mothers, health workers and boda-boda riders can improve the community-based referral process and deliveries in the rural community of Busoga region in Uganda.

Methods: The study was a 2-arm cluster non-randomized control trial study design; with intervention and control groups from selected health centres and communities as the units of non-randomization. The study interventions involved the provision of incentives for mothers, health workers and boda-boda riders for duration of six months. The study used a mixed methods research design with both quantitative and qualitative approaches. Descriptive statistical analysis was computed using STATA version 14 for the quantitative data and thematic analysis for qualitative data.

Results: Findings revealed that incentives strongly improved community-based referrals and health facility deliveries in the study area. Mothers who delivered from health centres and transported by boda-boda transport were $70.5 \%$ in the intervention arm and only $51.2 \%$ in the control arm. Of the $70.5 \%$ of the mothers above, $69.4 \%$ were transported by trained boda-boda riders and only $30.6 \%$ were transported by un-trained boda-boda riders. The $69.4 \%$ mothers transported by trained boda-boda riders to health centres stated that boda-boda riders' response to their calls for transport improved from $4.3 \%$ to $21.3 \%$ in the 5 - 20 minutes interval. For the 21 - 30 minutes interval, the response improved from $31.4 \%$ to $69.6 \%$ in the intervention arm compared to $37.1 \%$ to $40.3 \%$ in the control arm. As the time interval increased, the boda-boda riders who delayed to respond to mothers' calls reduced. In the intervention arm, only $6.2 \%$ of the mothers stated that boda-boda riders' response took $31-60$ minutes time interval after the intervention compared to $54.9 \%$ before the intervention. There was little change in the control arm from $53.2 \%$ pre intervention to $41.2 \%$ post intervention. Similarly, the boda-boda riders' response to mothers' calls for transport reduced for the time interval of 60 minutes and above.

Conclusion: Incentives and creation of partnerships are very critical in achieving better health facility-based deliveries as a result of proper referral processes.

\section{Plain English Summary}

Incentives for mothers, health workers and boda-boda riders can improve the community-based referral process and deliveries in the rural communities. A 2 arm cluster non-randomized control trial study was conducted in Busoga region of Uganda with intervention and control groups from selected health centres and communities as the units of non-randomization. The study interventions involved the provision of incentives for mothers, health workers and boda-boda riders for duration of six months. A mixed methods research design was employed.

Findings revealed that incentives strongly improved community-based referrals and health facility deliveries in the study area. Mothers who delivered from health centres and transported by boda-boda transport were $70.5 \%$ in the intervention arm and only $51.2 \%$ in the control arm. $69.4 \%$ were transported by trained boda-boda riders and un-trained boda-boda riders transported only $30.6 \%$. Mothers reported that boda-boda riders' response to their calls for transport improved from $4.3 \%$ to $21.3 \%$ in the 5 - 20 minutes interval. For the 21 - 30 minutes interval, the response improved from $31.4 \%$ to $69.6 \%$ in the intervention arm compared to $37.1 \%$ to $40.3 \%$ in the control arm. In the intervention arm, only $6.2 \%$ of the mothers reported that response took $31-60$ minutes post intervention compared to $54.9 \%$ pre intervention. There was little change in the control arm.

Incentives and creation of partnerships are therefore very critical in achieving better health facility-based deliveries as a result of proper referral processes.

\section{Background}

Maternal and child health continues to be a largely overlooked aspect of health care system leading to major risks associated with pregnancy and childbirth [1]. This could be associated with lack of interest in the information and interventions provided to the mothers [2]. Further, the deteriorating health of mothers and children has affected the national and global economy [1, 3]. Most times, mothers and children are hospitalised with limited time for productivity of both patients and the attendants. Many 
interventions like training of health workers and health educating of mothers have been tried but with little improvement in the maternal results. Perhaps these interventions required accompaniment of incentives to fully attract the involvement of mothers and other key stakeholders in the struggle for the improvement of Maternal and Child Health $(\mathrm{MCH})$. Both the monetary and nonmonetary incentives have been instrumental in the improvement of deliveries at health centres. However, its sustainability has been questionable. It has generally affected the community-based referral processes and mothers cannot afford to reach health centres all the time to deliver.

According to Ekirapa-Kiracho et al. (2011), the voucher system as an incentive was introduced in eastern Uganda where community motorcyclists (boda-boda riders) accepted it in exchange for transport services for mothers to health centres during Antenatal Care (ANC), delivery and Postnatal Care (PNC) [4]. Initially, safe deliveries at health centres improved from 200 to over 500 deliveries per month in the intervention arm. However, there was no capacity for proper management of the voucher system for sustainability purposes. This has left the MCH services (deliveries inclusive) in the East - Central Uganda wanting.

In Malawi according to Akker et al. (2011), non-monetary incentives which included soap, baby blanket and traditional baby wrap increased deliveries by 87 percent especially in the rural areas. Together with the District Health Office (DHO), the local Non Government Organisation (NGO) provided the non-monetary incentives for almost 2 years. However, the improved health facilitybased deliveries did not last for a long period of time when support was reduced. Similarly, this particular incentive did not target the referral process and transportation of mothers to health centres during delivery and with pregnancy complications [5].

According to Ir, et al. (2015) in Cambodia results - based financing contributed to the improvement in deliveries in health centres from 19 percent to 57 percent after 5 years. This incentive was based on the accurate data extracted from the National Information Management System (NIMS) to motivate the health workers especially midwives under the Government Midwifery Incentive Scheme (GMIS) [6]. This was not different from the Indonesian study according to Ensor et al. (2008) where midwives in rural areas were given two thirds of income from private clinical practice [7].

Most of the studies which involved training of different stakeholders to improve maternal indicators did not consider much of the monetary incentives. The main focus of the studies was to provide knowledge as a non-monetary incentive though monetary incentives in form of allowances were later discovered to be vital. The Hunger Project (2017) in Ghana in partnership with the Ghana Health Service (GHS) trained Community Health Nurses (CHN) as midwife assistants in form of workshops, mentorships and coaching for them to have enough information to give mothers, to be able to record properly in registers and to report in time [8]. The health workers were pleased but the information received did not fully increase deliveries in the health centres. Similarly, nutrition improvement in Afghanistan for mothers to adopt healthy home practices was necessary [9] but the outcome was not desirable. The maternal education sessions aimed at providing information as an incentive by health workers and Community Health Extension Workers (CHEWs) to mothers at health centres and in community, but there was little improvement in deliveries [10]. This was not different from the eastern study by Namazzi et al. (2017) on training of CHEWs in assessing the danger signs in babies [11]. Unfortunately, in all these studies transporters of mothers to health centres / hospitals were not involved in the education sessions.

For effective uptake of the training intervention, incentives to mothers, boda-boda riders and other stakeholders were important. This was a motivation to the study participants. Different theories of motivation were considered to support the Busoga region study. According to Goodman (2011), incentives given to participants led to improved performance. This is well explained by the agency-based economic theories [12]. In management, organizational employees are expected to produce results as explained also by the agency-based economic theories but their commitment alone did not produce results [13]. This confers the reason for giving incentives to employees. In this case, the recruited boda-boda riders were monitored for productivity especially helping in the transportation of mothers. Operational mechanisms of how external incentives lead to performance improvement at the front line were a central concern of the field of organizational psychology [14]. External incentives for mothers, boda-boda riders and other stakeholders included allowances, free calls and bonus airtime, refreshments and recognition of best performers (helmets given to riders).

Further, process theories of motivation explained the contributing factors for employees to yield results for the institution or organization. For the case of boda-boda riders, external incentives were provided which the study investigated to conclude its 
relationship with community-based referral and health facility deliveries. Process theories refer to a system of ideas or statements that account for or explain a group of facts or phenomena related to the implementation of activities - how they should be planned, organized, and scheduled in order to be effective [15]. Process theories vary in scope and application areas. Process theories range from those seeking to explain the performance of organizations and work-team, to those dealing with the motivation, perceptions, organizational resources and support systems, and those that deal with how financial incentives influence performance.

Theories have been advanced to understand an individual's intrinsic and extrinsic motivation for work. These include those that seek to identify the factors essential for individual's motivation (content theories) such as Maslow's hierarchy of needs, McGregor's $X$ and $Y$ theories and Herzberg theory [16]. These theories address the human needs that give rise to motivated behaviour. These theories identify various "needs" essential for employee motivation, satisfaction and continued commitment to work. The needs arising from these theories range from basic ones such as food and shelter to higher ones such as recognition, growth and sense of accomplishment. Other needs relate to relationships with others and a sense of belonging. For this study, quarterly review meetings with boda-boda riders, VHTs and midwives were conducted where best performers were recognized and rewarded. Allowances and refreshments given to mothers, health workers, boda-boda riders and other individuals positively triggered their performance.

Similarly, in the context of human resource management related to community based referral and transportation of mothers to health centres to deliver, as an explicit concern for sustained health facility performance, Herzberg's motivation-hygiene theory offers more explanatory potential [17]. It identifies the short and long-term factors as well as personal and environmental factors for mothers and boda-boda riders' motivation. In brief, motivation-hygiene theory posits that two factors namely; motivators and satisfiers have different causal elements. The motivators relate to what a person does while the satisfiers relate to the situation in which the person does his/her work. For example, supervision, interpersonal relations, organizational rules, working conditions and salary are short-term satisfiers rather than motivators. The health workers', mothers' and boda-boda riders' satisfiers were refreshments, allowances given during training, payments made by mothers when transported, free calls to those who were in the closed caller user group and an airtime bonus. The absence of hygiene factors can create job dissatisfaction, but their presence does not necessarily motivate or create satisfaction. The motivators are related to elements that enrich a person's job; such as achievement, recognition, the work itself, responsibility, and advancement.

These motivators are associated with long-term positive effects in job performance [18]. In this case, training of the boda-boda riders, mothers and health workers increased on their knowledge to improve on the performance as a long-term effect. In particular, the use of financial rewards such as salary and bonuses are classified as hygiene factors with transient effects on results. The two factor theory has found broad application especially in managing and motivating knowledge-based productivity where tasks involve broad discretionary space from the employee. This situation is similar to health facility care and the community management of referrals where decision-making is delegated to health professionals, boda-boda riders and mothers [19].

\section{Methods}

\section{Study design}

The study was a 2-arm cluster non-randomized control trial study design; with an intervention and control groups from selected health centres and communities as the units of non-randomization. One of the study interventions was providing incentives for mothers, health workers (midwives and VHTs) and boda-boda riders and took place for a period of six months.

\section{Study setting}

The study was carried out in the rural districts of Busoga region that were participating in community studies at different levels in Uganda. Local level participants came from two districts of Bugiri and Iganga where study projects were conducted in selected sub counties that made up the intervention and control arms. These sub counties included; Nambale, Nabitende, Nawandala in Iganga district and Budaya Sub County in Bugiri district for the intervention arm while Nawaningi, Ibulanku and 
Makuutu in Iganga district and Nabukalu in Bugiri district formed the control arm. The intervention health facilities included; Bugono health centre IV, Kasambika health centre III, Nambale health centre III, Nawandala health centre III, and Namusiisi health centre III in Iganga district and Mayuge health centre III in Bugiri. While the control arm included; Makuutu health centre III, Bunyiiro health centre III, Busesa health centre IV in Iganga district and Nabukalu health centre III in Bugiri district.

The reason for choice of study area was that motorcycle ambulances had once been operating under a funded project and had not been sustained. Therefore the study aimed at testing a local initiative that is more sustainable since it used locally available motorcycle (boda-boda) groups mobilised with the aim of referring mothers for further management at the different levels of health centres.

\section{Study participants}

The participants in Table 1 were boda-boda riders, health workers (midwives and VHTs) and mothers. These were the primary target beneficiaries for the incentives and focus was based on these categories for this presentation in the intervention and control arms. Meanwhile, in the control arm, the study participants did not benefit from the incentives as indicated in Table 1.

Table 1

Study participants in both intervention and control arms

\begin{tabular}{|c|c|c|c|c|}
\hline \multirow[t]{2}{*}{$\begin{array}{l}\text { Categories of } \\
\text { participants }\end{array}$} & \multicolumn{2}{|c|}{$\begin{array}{l}\text { Total number of } \\
\text { participants }\end{array}$} & \multicolumn{2}{|l|}{ Study sub counties } \\
\hline & $\begin{array}{l}\text { Intervention } \\
\text { arm }\end{array}$ & $\begin{array}{l}\text { Control } \\
\text { arm }\end{array}$ & Intervention arm & Control arm \\
\hline Boda-boda riders & 100 & 92 & \multirow{5}{*}{$\begin{array}{l}\text { Budaya, Nawandala, Nabitende } \\
\& \text { Nambale }\end{array}$} & \multirow{5}{*}{$\begin{array}{l}\text { Nabukalu, Nawaningi, Makuutu } \\
\text { and Ibulanku }\end{array}$} \\
\hline Midwives & 18 & 18 & & \\
\hline Mothers & 255 & 248 & & \\
\hline $\begin{array}{l}\text { Village Health Team } \\
\text { Members }\end{array}$ & 8 & 10 & & \\
\hline Total & 381 & 368 & & \\
\hline
\end{tabular}

\section{Recruitment of participants}

The mothers were recruited from the antenatal register based on their willingness and meeting the inclusion criteria and in the selected study villages and sub counties. Mothers in their third trimester were recruited purposely to determine the impact of the incentives. Mothers were recruited in both the intervention and control arms.

The boda-boda riders were recruited basing on their operating stage (workstation), activeness and willingness to take part in the study and be trained. Boda-boda riders who were from boda-boda stages within the study sub counties who had no registered crime with police were selected.

The midwives from the selected health facilities were recruited basing on their expressed interest and experience in research. They must have worked with the health facility for over 6 months.

The VHTs were recruited purposely based on inclusion criteria and their presence in the selected villages together with their willingness to take part in the study. Also, active VHTs were considered for this study.

Consent was sought from all the participants (midwives, boda-boda riders, VHTs and mothers) before they were initiated into the study.

\section{Sampling techniques of participants}

For this study, purposive and random sampling techniques were employed. Study participants were identified from different data sources; that is, document review of the delivery register, ANC register and PNC register in the selected health centres, VHTs 
register at the district health office and boda-boda riders' register at the village, sub county or district levels.

\section{Training of stakeholders and other incentives}

The training was preceded by a well-designed training program for the selected stakeholders who included the boda-boda riders, health workers and mothers. Despite the VHTs and midwives having some knowledge on maternal referrals, there was need for rapport building with the boda-boda riders. Four trainings were conducted in the selected four sub counties for the intervention for the boda-boda riders and health workers. The training lasted for five (5) days. Mothers on the other hand were trained from the health centres during the ANC visits. Participants in the training especially the boda-boda riders were facilitated and compensated for the days in training since some of the riders did not own motorcycles and were supposed to deposit their commissions to the motorcycle owners. Sessions were conducted for a relatively short period of time (9am - $2 \mathrm{pm})$ daily to allow the riders continue with their daily work after the training since there was demand for their services in the community. However, VHTs and midwives were also facilitated with allowances in the training.

Training sessions of mothers at health centres took a short time of around 1-2 hours. This was based on their vulnerability. These were mothers in their third trimester. As an incentive for the training, mothers were given only refreshments on every ANC visit.

\section{The closed caller user group and the bonus airtime}

Participants who benefited from the closed Caller User Group (CUG) included; mothers, boda-boda riders, VHTs and midwives. Only participants in the intervention arm benefited from the CUG. On consent, participants were registered by the MTN telecommunication company to benefit from the free communication calls between all the members in the group.

Also, bonus airtime of 10,000 Uganda shillings was given to each member of the group for communicating to other members who were not in the group during times of emergency. This was in a situation where the boda-boda rider was far and would use the bonus airtime to call another boda-boda rider at the stage regardless of whether he was in the CUG or not.

\section{Fleet management and transport fares of boda-boda services for mothers}

In order for mothers to fully benefit from the boda-boda services, they were continuously encouraged to save money in the savings boxes for a sustainable motivation of boda-boda riders. This money was to pay for mothers' transport fares for bodaboda services. It motivated the boda-boda riders because they were assured of their payments for the services. There was increased access to and quality of health care services in local communities. Simply, this concept is termed as franchising for health services and is not different from franchises in business.

Franchising is defined as a system of marketing goods and/or services and/or technology, which is based upon a close and ongoing collaboration between legally and financially separate and independent undertakings, the franchisor and its individual franchisees [20].

Specifically, in this study, a group was formed called Mama Boda-boda (Motorcycle) Transport System (MBTS) which picked interest in boda-boda transport and communication link between mainly the boda-boda riders and pregnant mothers. The intention was to have mothers deliver in health facilities under skilled personnel to reduce on the maternal and neonatal mortality. Both boda-boda riders and pregnant mothers were to benefit from the innovation. Boda-boda riders were to benefit from the transport fares paid by the mothers while the mothers were to automatically enjoy the privilege of having transport at their exposure. The franchisor in this case was the mama - boda-boda transport system which granted individual franchisees (mothers and boda-boda riders) the right and obligation to conduct business in accordance with the franchisor's/study concept.

There is a mutual agreement for each party to benefit and at a relatively good cost. Terms of payment for the service may be agreed on by the two parties. However, in this study, the concept of saving money in a small box to enable a mother to pay the boda-boda rider when referred to a health centre was necessarily adopted. The intention was to enable mothers to pay riders for the transport services. This is locally termed as "savings box". Mothers save money in this box and break the box when going to 
health facilities to deliver. Saving money is usually a tedious task that requires a high degree of self-control for many of the mothers (Seitz et al., 2013). However, saving in the boxes was considered sustainable compared to other incentives. During the training, mothers were equipped with knowledge about saving, the savings box as well as its merits. In this study, there were no terms agreed on for mothers when paying the boda-boda riders. The terms of payment for boda-boda transport services were mutually agreed upon between the mothers and the boda-boda riders in accordance with the distance travelled to reach the health facility.

\section{Research instruments}

\section{Questionnaires}

We had baseline and exit interview questionnaires that were filled at the health facility for the mothers who used boda-boda transport in to the health centres.

\section{Interview guide}

Data was also collected using the key informant and in-depth interview guides for the boda-boda riders, mothers, VHTs and midwives in selected health facilities of the intervention and control arms.

\section{Focus group discussions}

This was done at baseline as an entry point and later on when executing the study. It consisted of different stakeholders in the study.

\section{Document review checklist}

this was designed to capture data from the secondary source. These included; delivery registers, ANC registers and PNC registers.

\section{Data analysis}

Data analysis of descriptive statistics was computed using STATA version 14 for the quantitative data. Paired t-tests of independence were used to determine the statistical significance of the different variables with $p$-value set at 0.05 and confidence interval at 95 percent.

In order for the study to be informative, difference-in-difference (DID) framework was used. The simplest form of the DID design is a special case in which there are only two groups observed in two time periods. DID was used to determine the change effect based on the average value and its statistical significance.

Atlas Ti version 7 was used for qualitative analysis. It involved re-reading the interview transcripts to identify themes and sub themes that emerged from the respondents' answers during the FGDs, KIls and IDIs. The arrangement for analysis was based on the topics and questions formulated for the interviews in order to synthesize the answers to the proposed questions.

\section{Results}

The results are presented in terms of the incentives that the different participants in the study got and how they affected the outcomes in terms of maternal health outcomes and these included; the training component, closed caller group, the bonus airtime and other general incentives that the different categories of participants got, and how these impacted the research outcome. These incentives were in form of allowances, payments for the services, refreshments, free calls and bonus airtime. Non-monetary incentives included recognition and/or rewarding of best performers during meetings.

\section{Training incentives and its impact}


Training incentives included; training allowances to midwives, boda-boda riders and VHTs. Also, mothers were given refreshments at the health centre during ANC visits. Numbers of mothers who delivered from health centres and were transported by boda-boda transport were 70.5 percent in the intervention arm and only 51.2 percent in the control arm. Also, of the 70.5 percent of the mothers who delivered from the health centres, 69.4 percent were transported by trained boda-boda riders and only 30.6 percent of the mothers were transported by un-trained boda-boda riders.

This is supported by the inspirational statements which were made by the different motivated stakeholders during and after the training. Excitement, friendship creation and participatory learning were witnessed during and after the training. One of the participants noted;

...I have learnt a lot from the training, for example the importance to take mother to the health facility in time. Since you stated that communication was simplified for mothers to contact us, then we shall also respond very fast

The health workers noted the need for team work and commitment by all those involved in the study to be able to meet the needs of mothers who are in dire conditions of child birth.

The excited VHTs who participated in the training indicated that they should not only enjoy the allowances which were given to them but also emphasised that this training was very timely especially for the boda-boda riders.

Another VHTs in the training room emphasised to the boda-boda riders that they should put into practice what was learnt.

...Knowledge building and sharing on understanding of $\mathrm{MCH}$ is now seen on your faces, especially the boda-boda riders who now know the need to support the mothers especially in timely transporting to the health centre for delivery. Let us be practical.

\section{Transport fare payments by mothers to the boda-boda riders}

Mothers were encouraged to save money in small boxes which were broken at the time mothers were experiencing labour pains. Boda-boda riders were able to respond to mothers' calls very fast because they were very sure of their payments when they offered the transport services.

One of the stage coordinators of the boda-boda riders in an in-depth interview indicated that in the past, he did not take it urgent to provide transport to mothers in labour or mothers with birth related complications to the health centres. This is because labouring mothers did not have money to pay them on arrival at the health centres.

...what we have learnt today is important and I am committed to participating in this study to save mothers, even if it means taking them to the health facility on credit. However, since they are saving it will not be a challenge for them to pay us.

\section{Free calls, bonus airtime and time interval taken for the boda-boda rider to arrive}

The incentive for the CUG was the free calls and the bonus airtime. Participants who majorly benefited from the closed caller user group (CUG) included; mothers, health workers and boda-boda riders. The free calls and bonus airtime enjoyed in CUG contributed to the reduction in time boda-boda riders took to respond to mothers' calls. See results in Table 2. 
Table 2

Communication by mothers for boda-boda transport

\begin{tabular}{|c|c|c|c|c|c|c|c|}
\hline \multirow{3}{*}{ Yes } & & \multicolumn{2}{|l|}{ Pre } & \multicolumn{4}{|l|}{ Post } \\
\hline & & Interv. & Control & Interv. & Control & DID & P- \\
\hline & & & & & & & \\
\hline \multirow[t]{4}{*}{$\begin{array}{l}\text { Time interval taken for the boda-boda rider to } \\
\text { arrive when contacted by the mother (Yes) }\end{array}$} & $\begin{array}{l}5-20 \\
\text { minutes }\end{array}$ & $\begin{array}{l}11 \\
(4.3 \%)\end{array}$ & $\begin{array}{l}18 \\
(7.3 \%)\end{array}$ & $\begin{array}{l}54 \\
(21.3 \%)\end{array}$ & $\begin{array}{l}41 \\
(16.7 \%)\end{array}$ & 0.391 & 0.000 \\
\hline & $\begin{array}{l}21-30 \\
\text { minutes }\end{array}$ & $\begin{array}{l}80 \\
(31.4 \%)\end{array}$ & $\begin{array}{l}92 \\
(37.1 \%)\end{array}$ & $\begin{array}{l}177 \\
(69.6 \%)\end{array}$ & $\begin{array}{l}100 \\
(40.3 \%)\end{array}$ & & \\
\hline & $\begin{array}{l}31-60 \\
\text { minutes }\end{array}$ & $\begin{array}{l}140 \\
(54.9 \%)\end{array}$ & $\begin{array}{l}132 \\
(53.2 \%)\end{array}$ & $\begin{array}{l}16 \\
(6.2 \%)\end{array}$ & $\begin{array}{l}102 \\
(41.2 \%)\end{array}$ & & \\
\hline & $\begin{array}{l}60+ \\
\text { minutes }\end{array}$ & $\begin{array}{l}24 \\
(9.4 \%)\end{array}$ & $\begin{array}{l}6 \\
(2.4 \%)\end{array}$ & $\begin{array}{l}8 \\
(2.9 \%)\end{array}$ & $\begin{array}{l}5 \\
(1.8 \%)\end{array}$ & & \\
\hline
\end{tabular}

The bonus airtime and free calls were important in the coordination of mothers' transport to health centres. These motivated mothers who were in the CUG to easily contact boda-boda riders for transport services. Similarly, boda-boda riders were able to call back mothers and health workers.

69.4 percent mothers who were transported by the motivated trained boda-boda riders to health centres to deliver stated that boda-boda riders' response to the calls they made improved from 4.3 percent to 21.3 percent for the 5-20 minutes interval in the intervention arm. For the 21-30 minutes interval, boda-boda riders' response improved from 31.4 percent to 69.6 percent in the intervention arm compared to 37.1 percent to 40.3 percent in the control arm.

Interestingly, as the time interval increased, the number of boda-boda riders who delayed to respond to mothers' calls reduced. For instance, in the post intervention in the intervention arm, only 6.2 percent of the mothers stated that boda-boda riders took 31-60 minutes time interval to respond to their calls compared to 54.9 percent in the pre intervention. There was little change in the control arm from 53.2 percent in the pre-intervention to 41.2 percent in the post-intervention. Similarly, the number of bodaboda riders who took time to respond to mothers calls when contacted for transport reduced for the time interval of 60 minutes and above as reflected in Table 2.

According to the DID model of analysis, the intervention was impactful. The time interval boda-boda riders took to respond to mothers' calls for transport kept on reducing. The average value for the time interval boda-boda riders took to arrive when contacted was 0.391 . This was found to be statistically significant to the change effect as shown in Table $2(p=0.000)$. Therefore, the allowances and other incentives improved on the responses made by the boda-boda riders when contacted by mothers for transport to health centres and had effect on the time interval it took riders to reach mothers.

\section{Influence of time intervals on deliveries at health centres}

Regression analysis of the time interval boda-boda riders took to respond to mothers' calls had a statistically significant influence on the deliveries at health centres. See results in Table 3. 
Time interval and its association with health facility-based deliveries

\begin{tabular}{|c|c|c|c|}
\hline Predictive variable & & Odds ratio (95\%) & $\begin{array}{l}\mathrm{P}- \\
\text { value }\end{array}$ \\
\hline \multirow[t]{2}{*}{ Category } & Control & 1 & \\
\hline & Intervention & $\begin{array}{l}1.173(0.760 \\
4.501)\end{array}$ & 0.001 \\
\hline \multirow[t]{3}{*}{$\begin{array}{l}\text { Time interval taken for the boda-boda rider to arrive when contacted by the } \\
\text { mother }\end{array}$} & $\begin{array}{l}5-20 \\
\text { minutes }\end{array}$ & 1 & \\
\hline & $\begin{array}{l}21-30 \\
\text { minutes }\end{array}$ & $\begin{array}{l}0.344(0.189 \\
0.626)\end{array}$ & 0.000 \\
\hline & $\begin{array}{l}31-60 \\
\text { minutes }\end{array}$ & $\begin{array}{l}0.027(0.007 \\
0.103)\end{array}$ & 0.000 \\
\hline
\end{tabular}

The incentives to mothers, boda-boda riders and other stakeholders increased their motivation and improved deliveries in health centres. The motivation of these stakeholders reduced on the time boda-boda riders took to respond on the mothers' calls when contacted for transport to health centres. Results show that there was a statistically significant influence of time interval on health facility-based deliveries. Pregnant mothers who contacted boda-boda riders at the different intervals for transport to health centres in the intervention arm were 1.173 times more likely to deliver from health centres compared to those in the control arm $(p=0.001 ; \mathrm{Cl}=0.760-4.501)$.

Considering the statistical significance of the time intervals, the 5-20 minutes interval which boda-boda riders took to arrive when contacted by mothers had no association with deliveries at health centres. The other time intervals $(21-30$ minutes and 31-60 minutes were statistically significantly influencing the deliveries in health centres $(O R=0.344 ; p=0.000 ; C l=0.189-0.626$ and $\mathrm{OR}=0.027 ; \mathrm{p}=0.000 ; \mathrm{Cl}=0.007-0.103$ respectively).

During an FGD in the intervention arm specifically in the pre-intervention phase, boda-boda riders were encouraged to be quick and respond whenever a mother contacts them. They were assured of immediate payments on delivery of mothers at the health centres. Mothers had saved money in the saving boxes.

"...Do not take much time to go to mothers whenever they call you. Just know, that is a hard moment especially when in labour. Mothers cannot walk at that time. These are our relatives, wives, daughters and sisters. Learn to rush to them." One of the members of the group urged the colleagues.

\section{Rewards of best performers - non-monetary}

Quarterly meetings in the different sub counties in the intervention arm were conducted. In these meetings, discussions were focussed on the improvement of community-based referrals and increased deliveries in health centres. Boda-boda riders who transported the biggest number of mothers were rewarded with helmets and recognition during meetings. The majority of the boda-boda riders appreciated the importance of the meeting.

"...In these meetings we are able to present our challenges we face in the transportation of mothers such that solutions are discussed here." One of the boda-boda of riders stated.

Another one said;

"...I'm not the best boda-boda rider pronounced in this meeting and this has given me the zeal to work hard such that next time I become one of the best riders in my sub county".

Similarly, in addition to the routine allowances which were given to the different midwives for the recruitment and registration of mothers in the CUG, boda-boda riders gave a feedback of the best midwives who were cooperative. These were rewarded and recognised before the boda-boda riders in the meetings.

Page 10/16 
"... I did not know that by the humble interaction with the local boda-boda riders I was doing something appreciated by most of them. This has opened my mind and now I know the reason for the increasing number of deliveries at my health centre". A midwife who was excited stated in one of the meetings.

\section{De-motivation of boda-boda riders}

Boda-boda riders raised some of the challenges which were experienced during the time of implementation of the study. This was during focus group discussions and key informant interviews. At times, these challenges act as de-motivators. Mothers remain affected with lack of transport means to health centres to deliver under skilled personnel. Some of these challenges included; lack of ownership of the motorcycles, failure of mothers to save money in the savings boxes and the non payments on delivery of mothers to health centres, mothers delivering on their way to health centres, bad roads, and theft of the motorcycles amongst others. But because of good training, incentives and knowledge attained during the training, the boda-boda riders were committed to continue with the good work.

"...Some of the riders do not own motorcycles. The people who buy for them the motorcycles tend to take it back home at night. This becomes difficult to transport mothers at night. Secondly, the owners of the motorcycles want the money paid immediately, therefore becoming very difficult for mothers who do not possess money at the time". A boda-boda rider at Buzaya stage said.

"Many times women and their families cannot or do not pay, even after taking them to the health facility. Some families do not adequately prepare for the expense of boda-boda transport during labour". Another boda-boda rider added.

However, the midwives noted that much as there were challenges in place, there was an improvement in the maternal outcome because of the motivation of the health workers and other key stakeholders.

"...the incentives improve the maternal and neonatal outcomes." This was in the intervention arm.

"...the boda-boda riders who own motorcycles are more considerate to saving lives of pregnant mothers and act much faster now days when they are called to transport a pregnant mother to the health facility." Another midwife noted.

It was not different for VHTs as it was noted that they were more vigilant and motivated due to the incentives given to them.

...it is very easy for me to call the midwife to see if she is at the health centre when I have a woman who is in labour and had complication as I refer accordingly.

\section{Discussion}

Incentives are a key component of performance in this study. All the different categories of participants were motivated in one way or the other with incentives. The different participants were given incentives to take part in the study; these participants are the health workers, the boda-boda riders, and the pregnant women in their third trimester. This was not different from other studies. According to Ekirapa-Kiracho et al. (2011) in the voucher system as an incentive introduced in eastern Uganda, like in the rural Busoga sub region study, community motorcyclists accepted to transport mothers to health centres during antenatal care (ANC), delivery and postnatal care (PNC) [4]. Further, in [4]'s study, safe deliveries at health centres improved from 200 to over 500 deliveries per month, and similarly, deliveries increased from 52 percent to 70.5 percent in the rural Busoga sub region study.

The introduction of the non-monetary incentives in the rural Busoga sub region study like it was in the Malawi study, resulted in the improvement in the deliveries at the health centres. The rural Busoga sub region study incentives were helmets and recognitions during meetings unlike in Malawi where soap, baby blanket and traditional baby wraps were distributed according to Akker et al. (2011), these too had similar results (improved deliveries) [5]. Non-monetary incentives in Busoga region study included; free calls and bonus airtime for boda-boda riders and mothers who were in the closed caller user group. Incentives were given for a period of 6 months and deliveries for mothers transported by boda-boda riders increased to 70.5 percent compared to 87 percent in the rural areas of Malawi for the 2 years [5]. The study has not tested the sustainability of having good results without the intended incentives to the different stakeholders.

Page 11/16 
Mothers were able to call members of the group even without airtime or credit on their phones. This made it easy to link the mothers to the VHTs, boda-boda riders and the health workers (midwives) in the health centres for participating sites and cheap to call the boda-boda riders to take the mothers to the health facilities without any delays. The free calls and bonus airtime supported in better communication time and response for taking the mothers to the health facilities. In situations where the boda-boda rider was far, a mother would use the bonus airtime to call another boda-boda rider at the stage regardless of whether he was in the caller group or not. This increased the number of health facility deliveries from 52 percent to 70.5 percent in the sub region. However, like in other studies, its sustainability in Africa and Busoga region in particular is hindered by poverty though improved deliveries and maternal mortality reduction remains a priority under "Goal 3: Ensure healthy lives and promote well-being for all at all ages" in the new Sustainable Development Goals (SDGs) agenda through 2030 [21]. This will eventually create another communication gap between mothers and the boda-boda riders leading to the first and second delay in the referral process [22, 23], yet community referral is crucial in improving the deliveries at health centres [24].

While for the VHTs, referral was made easier since they were able to call the midwife in the study facility and give their quick assessment of the situation of the mother before she reaches the health centre. The midwife prepared depending on the information shared by the VHT who was referring the mother from the community. This is discussed adequately in the literature review, as noted. The health of mothers and their new-born babies is crucial in health services management as it is often affected by mothers delivering at home, and this is attributed to many factors [25]. Timely and functional referral system for mothers in the community is important as it backs up antenatal care, labour and delivery at low and high level health facilities [26]. This was exhibited in the rural Busoga sub region study.

Like the voucher system in [4]'s study, the rural Busoga region study incorporated a savings system for the expectant mothers to put a minimum of 200 shillings in a "savings box" per day for almost 3 months before they give birth. This money was for the basic needs during delivery including transporting the mother to the health facility and motivated boda-boda riders to willingly transport mothers to health centres. This incentive is sustainable since majority of mothers are capable of saving in the boxes. The rural Busoga sub region study was not different from [8] in Ghana, [9] on nutrition improvement in Afghanistan and [10] on provision of information as non-monetary incentives; instead it worked out very well on the referral mechanism which increased deliveries in the rural health centres in Busoga sub region. Mothers, health workers and boda-boda riders having information and communication systems, their attitude towards community referrals changed and it was instrumental in improving some of the maternal health indicators. This is crucial in reducing the delays to seek quality healthcare services [27]. A lot which was left to be desired as far as the reduction of maternal mortality ratio (MMR) and neonatal mortality rate (NMR) in [28]'s study was addressed by the training of the different stakeholders which provided the right information for their proper mindset change.

The other forms of incentives were monetary to midwives, boda-boda riders and VHTs and results were realised. Trainings like in Afghanistan Cimini (2017) were source of transport refund and forms safari day allowances at the existing rates as an incentive for the selected stakeholders and contributed to results as reflected in the rural Busoga study. Similarly, [11] trained CHEWs who benefited from the allowances and results were realised. In the rural Busoga study, the midwives, boda-boda riders and VHTs received allowances and contributed to the improvement in the deliveries at health centres.

\section{Methodological considerations}

Although we tried to reach all the members in the study population and several categories of stakeholders who might influence the intervention, we were unable to interview some key stakeholders like some opinion leaders were not. Another limitation of this study is that the views of those interviewed may not be generalised to the entire institutions they serve or work for. Further still the views of stakeholders may change with time. Since some of the incentives were monetary, its sustainability is still questionable. However, despite the inherent limitations, stakeholder analysis is a vital tool in informing the design of any form of health systems research or intervention.

\section{Conclusion}


The incentives have been urged as an enormous way to better maternal and neonatal outcomes especially in rural communities in the less developed countries. Incentives along the maternal health chain are key and the initiative of incentivising the three categories of stakeholders (the health workers- midwives, the VHTs and the boda-boda riders) with the closed caller group for free calls, bonus airtime and an extra allowance for the health workers has demonstrated that partnership are very critical in achieving better results or maternal outcomes especially the health facility-based deliveries.

The incentives have the potential to have the boda-boda riders more interested and committed to transporting mothers to the health facilities as a priority to other customers since they feel obliged and this is a key component in addressing the challenges of complications for women who are at the verge of child birth.

It also addresses the other challenges of response time as it is clear that in developing countries most maternal and neonatal deaths can be prevented if there is a robust system to refer, transport and manage the delivery process especially for mothers with complications.

However, the following recommendations for improving community-based referral as well as health facility deliveries are made. Government should support riders through SACCOs to buy and own motorcycles. Savings boxes should be mandatorily acquired by mothers during the first ANC visit in all health centres in the region and the country at large to gather enough money for transport fare and other necessities during time of delivery. Boda-boda riders should be branded for easy identification since they are all willingly transporting mothers to health centres to deliver.

\section{Limitations Of The Study}

Some of the mothers gave disconnected phone numbers and this meant that the VHTs had to do further physical follow-up.

The boda-boda riders in some instances did not have motorcycles to transport the mothers when they were contacted, and in a few instances boda-boda riders' phones were off.

\section{Abbreviations}

VHTs.....Village Health Teams

ANC ......Antenatal Care

PNC......Postnatal Care

CUG...Closed Caller User Group

WHO....World Health Organisation

UNCST... Uganda National Council for Science and Technology

NIMS...National Information Management System

CHEWs.....Community Health Extension Workers

DID...Difference-in-Difference

MMR....Maternal Mortality Ratio

NMR....Neonatal Mortality Rate

SDGs.....Sustainable Development Goals

CHN......Community Health Nurses

Page 13/16 
GHS...Ghana Health Service

GMIS....Government Midwifery Incentive Scheme

$\mathrm{MCH}$.....Maternal and Child Health

NGO...Non-Government Organisation

DHO....District Health Office

\section{Declarations}

\section{Ethical approval and consent to participate}

Ethical approval to conduct the study was provided by the Institutional Review Board at Uganda Martyrs University - Nsambya hospital and Uganda National Council for Science and Technology (UNCST). Voluntary informed consent was then individually obtained from all the study participants.

\section{Consent for publication}

All the co-authors have given their consent to publish this manuscript.

\section{Availability of data and materials}

Data is available and will be submitted on request.

\section{Competing interests}

The authors declare that they have no competing interests.

\section{Funding}

No funding was received for the entire process of carrying out this research study and for the publication of this manuscript.

\section{Authors' contributions}

KMM conceived the study idea. KP, KRK, KMM, JFM, AY, and OGO designed the study and wrote the protocol. KMM, DGM and WI designed the data collection tools. KMM, IW, DGM participated in data collection. KMM, DGM, PK and OGO undertook the analysis. KMM, DGM, IW and AY wrote the manuscript. All authors critically revised, read and approved the final manuscript.

\section{Acknowledgements}

We would like to thank Mohammed Mukalu and Ronald Mali for their support in data collection. We are also grateful to the study participants and the centre staff in the study region for their contributions to this study.

\section{References}

1. WHO. Scaling up Mumbai's Maternal Health Referral System through Implementation Research.2019."https://www.who.int/alliance-hpsr/projects/sneha2017/en/" https://www.who.int/alliance- 
hpsr/projects/sneha2017/en/.

2. Patel S, Awoonor-Williams JK, Asuru R, Boyer CB, Tiah JAY, Sheff MC, et al. Benefits and Limitations of a CommunityEngaged Emergency Referral System in a Remote, Impoverished Setting of Northern Ghana. Global health science practice. 2016;4(4):552-67. https://doi.org/10.9745/GHSP-D-16-00253.

3. $\mathrm{MOH}$. Uganda Health Systems Strengthening Project. 2017. https://www.newvision.co.ug/digital_assets/8455133e-589b4292-8c0d.

4. Ekirapa-Kiracho E, Waiswa $P$, Rahman $\mathrm{MH}$, et al. Increasing access to institutional deliveries using demand and supply side incentives: early results from a quasi-experimental study. BMC Int Health Hum Rights. 2011;11:11. https://doi.org/10.1186/1472-698X-11-S1-S11.

5. Akker TVD, Radge G, Mateyu A, Mwagomba B, Bemelmans M, Reid T. Can non-monetary incentives increase health facility deliveries? The experience in Thyolo District, Malawi. International Health. 2011;3(1):66-8. https://doi.org/10.1016/j.inhe.2010.11.001.

6. Ir P, Korachais $\mathrm{C}$, Chheng $\mathrm{K}$, et al. Boosting facility deliveries with results-based financing: a mixed-methods evaluation of the government midwifery incentive scheme in Cambodia. BMC Pregnancy Childbirth. 2015. https://doi.org/10.1186/s12884-015-0589-x.

7. Ensor T, Quayyum Z, Nadjib M, Sucahya P. Level and determinants of incentives for village midwives in Indonesia. Health Policy Plann. 2009;24(1):26-35. https://doi.org/10.1093/heapol/czn040.

8. Hunger Project Ghana. Training of Community Health Nurses (CHN) as midwives assistants to address the shortage of midwives at the Community Health Planning and Services (CHPS) compounds in three regions. 2017.

9. Cimini GG. Calretinin Immunoreactivity in the Human Testis Throughout Fetal Life. cellular Physiology. 2017; 232 (7).

10. Prickett KC, Augustine JM. Maternal Education and Investments in Children's Health. 2015. https://onlinelibrary.wiley.com/doi/pdf/10.1111/jomf.12253.

11. Namazzi G, Okuga M, Tetui M, Kananura R, Kakaire A, Namutamba S, et al. Working with community health workers to improve maternal and newborn health outcomes: implementation and scale-up lessons from eastern Uganda. Global Health Act. 2017.

12. Goodman CO. Health facility committees and facility management. Bossert\& Beauvais. 2011.

13. Johns G. 'Presenteeism in the workplace: A review and research agenda'. Journal of Organizational Behavior. 2010;31(4):519-42.

14. Bjrkman MA. 'When is community-based monitoring effective? Evidence from a randomized experiment in primary health in Uganda'. Journal of the European Economic Association. 2010;8(2-3):571-81.

15. El-Jardall F, Saleh S, Ataya N, Jamal D. Design, implementation and scaling up of the balanced scorecard for hospitals in Lebanon: policy coherence and application lessons for low and middle income countries. Health Policy journal. 2011;2011103:305-14.

16. Tumushabe GM-T. Monitoring and Assessing the Performance of Local Government Councils in Uganda: Background, Methodology and Score Card, Kampala. Kampala: ACODE Policy Research Series; 2010.

17. Chen S. Corporate Board Governance and Risk Taking. Computational Risk Management.Springer Heidelberg. 2014.

18. Machingura FLR. 'Supporting the role of health centre committees: A training manual -. Pilot edition', TARSC, CWGH: Harare. 2011.

19. McCoy D, Hall J, Ridge M. A Systematic Review of the Literature for Evidence on Health Facility Committees in Low-and Middle-Income Countries. Health Policy Plann. 2012;27(6):449-66.

20. Koehlmoos TPGR. The effect of social franchising on access to and quality of health services in low-and middle-income countries. Cochrane Database of Systematic Reviews. 2009; 1. DOI:10.1002/14651858.C.

21. Kaye D, Kakaire O, Osinde M. Systematic review of the magnitude and case fatality ratio for severe maternal morbidity in sub-Saharan Africa between 1995 and 2010. BMC Pregnancy Childbirth. 2011;11:65. 
22. Thaddeus S. Too far to walk: maternal mortality in context. Johns Hopkins University. 1994. https://pdfs.semanticscholar.org/b417/80532a0b5d28547b1f659e64dacf36eac98d.pdf.

23. Health Africa. Academy for Educational Development. 1875 Connecticut Ave. NW Washington DC. 2010.

24. Ssebunya R, Matovu JKB. Factors associated with utilization of motorcycle ambulances by pregnant women in rural eastern Uganda: a cross-sectional study. 2016. https://www.ncbi.nIm.nih.gov/pmc/articles/PMC4778302/.

25. Hussein JK. What kinds of policy and programme interventions contribute to reductions in maternal mortality? The effectiveness of primary level referral systems for emergency maternity care in developing counties. 2011.

https://eppi.ioe.ac.uk/cms/Portals/0/PDF\%20reviews\%20and\%20summaries/Maternal\%20mortality\%202011Hussein.pdf?, 163837-720.

26. Pembe AB. Effectiveness of maternal referral system in a rural setting: a case study from Rufiji district, Tanzania. BMC Health Serv Resv. 2010;10:PMC3003655.

27. Program for Appropriate Technology in Health [PATH]. (2013). Referral Communication. Technology Opportunity Assessment Prepared for the Merck for Mothers Program.. http://sites.path.org/mnhtech/files/2013/07/Referralcommunication_2.

28. Nabudere HA. An Evidence Brief for Policy. Improving Access to Skilled Attendance at Delivery. 2011. http://www.who.int/evidence/assessing/sure/SBAfullreport2011.pdf. 